\title{
Can Low-Resolution Airborne Laser Scanning Data Be Used to Model Stream Rating Curves?
}

\author{
Steve W. Lyon ${ }^{1, *}$, Marcus Nathanson ${ }^{1, \dagger}$, Norris Lam ${ }^{1, \dagger}$, Helen E. Dahlke ${ }^{2, \dagger}$, \\ Martin Rutzinger ${ }^{3,4, \dagger}$, Jason W. Kean ${ }^{5, \dagger}$ and Hjalmar Laudon ${ }^{6, \dagger}$
}

1 Department of Physical Geography, Stockholm University, Stockholm 10691, Sweden; E-Mails: marcus.nathanson@natgeo.su.se (M.N.); norris.lam@natgeo.su.se (N.L.)

2 Department of Land, Air and Water Resources, University of California_Davis, Davis, CA 95616, USA; E-Mail: hdahlke@ucdavis.edu

3 Institute of Geography, University of Innsbruck, Innsbruck 6020, Austria;

E-Mail: martin.rutzinger@uibk.ac.at

4 Institute for Interdisciplinary Mountain Research, Austrian Academy of Sciences, Innsbruck 6020, Austria; E-Mail: martin.rutzinger@oeaw.ac.at

5 U.S. Geological Survey, Denver, CO 80225, USA; E-Mail: jwkean@usgs.gov

6 Department of Forest Ecology and Management, Swedish University of Agricultural Sciences, Umeå 90183, Sweden; E-Mail: hjalmar.laudon@slu.se

$\dagger$ These authors contributed equally to this work.

* Author to whom correspondence should be addressed; E-Mail: steve.lyon@natgeo.su.se; Tel.: +46-8-16-4888; Fax: +46-8-16-4818.

Academic Editor: Jun Xu

Received: 8 December 2014 / Accepted: 16 March 2015 / Published: 24 March 2015

\begin{abstract}
This pilot study explores the potential of using low-resolution $\left(0.2\right.$ points $\left./ \mathrm{m}^{2}\right)$ airborne laser scanning (ALS)-derived elevation data to model stream rating curves. Rating curves, which allow the functional translation of stream water depth into discharge, making them integral to water resource monitoring efforts, were modeled using a physics-based approach that captures basic geometric measurements to establish flow resistance due to implicit channel roughness. We tested synthetically thinned high-resolution (more than 2 points $/ \mathrm{m}^{2}$ ) ALS data as a proxy for low-resolution data at a point density equivalent to that obtained within most national-scale ALS strategies. Our results show that the errors incurred due to the effect of low-resolution versus high-resolution ALS data were less than
\end{abstract}


those due to flow measurement and empirical rating curve fitting uncertainties. As such, although there likely are scale and technical limitations to consider, it is theoretically possible to generate rating curves in a river network from ALS data of the resolution anticipated within national-scale ALS schemes (at least for rivers with relatively simple geometries). This is promising, since generating rating curves from ALS scans would greatly enhance our ability to monitor streamflow by simplifying the overall effort required.

Keywords: topographic LiDAR; rating curves; streamflow monitoring; water resources

\section{Introduction}

Topographic light detection and ranging (LiDAR) technology is based on the emission of laser light in a defined wavelength and frequency and the corresponding collection of backscatter from an illuminated surface. Topographic LiDAR (also commonly referred to as laser scanning) has gained popularity for 3D surface mapping applications [1,2]. One major advantage of topographic LiDAR in comparison to traditional photogrammetric mapping using stereo and dense image matching is the ability of the laser beam to penetrate vegetation through canopy gaps. This allows generating area-wide high-resolution digital terrain models (DTMs) under forested and vegetated areas [3,4]. Depending on the required accuracies and areas of coverage, topographic LiDAR systems are commonly mounted on airborne (airborne laser scanning, ALS), terrestrial (terrestrial laser scanning, TLS) or other mobile laser scanning platforms. As the economic and processing limitations of topographic LiDAR data decrease, thereby increasing data coverage and data availability [5], there are increased capabilities in both large-scale and small-scale applications.

This is easily seen in the current trend towards the production of national-scale ALS scans. The Netherlands [6], Switzerland [7] and Denmark (www.gst.dk) were some of the first countries in Europe to have completed such a national ALS campaign. For instance, Denmark provides datasets with a resolution of about 0.5 points $/ \mathrm{m}^{2}$ and a resulting $1.5 \mathrm{-m}$ grid elevation model produced (and publicly available) with a $0.1-\mathrm{m}$ vertical resolution. Many other countries have ALS scans ongoing. Sweden [8] (www.lantmateriet.se) is currently in the process of establishing a national-scale ALS dataset with a density of about 1 to (at best) 0.5 points $/ \mathrm{m}^{2}$. The United States of America is also in the planning phase with the Center for LiDAR Information Coordination and Knowledge looking to establish a national-scale scan made up of various state-level scans and existing ALS datasets [9]. This push is complemented through efforts like OpenTopography (www.opentopography.org) in the United States of America that seek to facilitate community access to Earth science-oriented topography data and related tools and resources. As these data come online, researchers and techniques need to be prepared to utilize them to their fullest potential [10].

What is evident, however, from the span of current studies across the environmental literature is that topographic LiDAR data provide a large amount of geospatial information [11] of which only a small fraction is typically utilized [12]. For example, much existing research focuses on high-resolution ALS-based mapping of terrestrial hydrologic and hydraulic systems (e.g., [13,14]). ALS has also been utilized for the collection of topographic and geomorphological data [15] and for mapping in and along 
river channels $[16,17]$. High-resolution and highly accurate topographic data, like that available from ALS, are needed for monitoring of river corridors, particularly in connection with natural hazard management (e.g., [18-20]) or the investigation of geomorphological change of floodplains [21,22]. Höfle et al. [4] showed the potential for water surface classification and delineation of river systems. Recent advances have also been made in using ALS to investigate forest ecosystems and to improve forest management (e.g., [23-25]). While ALS can provide increased accuracy, challenges still exist in complex urban environments [26]. In such landscapes, TLS has been shown to provide finer resolutions allowing for improvement to, for example, urban flood modeling [27]. In addition, TLS techniques are gaining traction among ecologists for describing vegetation architecture and functioning (e.g., [28-30]). Still, relatively few studies have begun to utilize the current generation of topographic LiDAR to fill knowledge gaps remaining in our understanding of, for example, key hydrologic fluxes.

One of the more active fields of hydrological research has been the utilization of LiDAR data to characterize roughness and stream geometry for use in hydraulic modeling. Traditionally, LiDAR data have allowed for characterization of distributed roughness maps for use in hydraulic modeling [31-33], leveraging relationships between vegetation height and hydraulic roughness from flume studies [34,35]. Abu-Aly et al. [36] offered a divergent methodology to utilize LiDAR data employing the approach from Katul et al. [37] to quantify hydraulic roughness as a function of vegetation height and water depth via a 2D hydraulic model. Nathanson et al. [38] demonstrated that high-resolution ALS data (more than 2 points $/ \mathrm{m}^{2}$ ) can contain enough information on the stream channel geometry to model stage-discharge relationships (rating curves) under certain conditions for relatively simple channel geometries. The rating curve is the functional relationship that allows for stream discharge monitoring based on direct observation of water height (stage) in a stream channel. What remains to be seen is if such approaches are viable at the resolutions expected for national-scale, low-resolution ALS acquisitions (i.e., resolutions of about 0.5 points $/ \mathrm{m}^{2}$ ).

The question thus becomes: How much information in terms of point cloud resolution (i.e., point density) is needed from an ALS survey to model rating curves with sufficient accuracy? Specifically, could low-resolution scans with a point density similar to those being carried out at national scales be used to estimate stage-discharge relationships? This pilot study seeks to answer these questions using the Krycklan experimental catchment (Figure 1) as a test bed with a relatively simple channel geometry. While this pilot study potentially represents a narrow range of rivers, the answers found here could have broad reaching potential to facilitate stream discharge monitoring.

\section{Materials and Methods}

\subsection{Test Site and Datasets}

The Krycklan catchment study area has its main outlet at $64^{\circ} 12^{\prime} \mathrm{N}$ and $19^{\circ} 52^{\prime} \mathrm{E}$ in the Svartberget research station as part of the national research infrastructure (www.fieldsites.se) located approximately $50 \mathrm{~km}$ northwest of Umeå, Sweden [39]. The site has a long history as a host to several multidisciplinary research projects related to water quality, hydrology, stream biodiversity and climate effects (e.g., [40-42]). High-resolution ALS data (Figure 1) were acquired at Krycklan's outlet during low-flow conditions using a helicopter-mounted TopEye MkII S/N 425 system [43]. These data form 
the core of this pilot study. An initial classification of ground echoes from non-ground echoes was achieved by a computational routine implemented at the Swedish University of Agricultural Sciences (SLU) evaluating the intensity and the number of echoes from each emitted laser pulse in the scan. This allowed for initial classification of the higher intensity ground echoes reflecting the region's relatively smooth ground surface topography and the lower intensity vegetation echoes. This information was then used to filter based on the identification of backscatter signatures caused by surface vegetation, which can be identified relative to backscatter signatures caused by ground topography (see [38] for more details). After filtering ground from non-ground echoes, the set of ALS data covering the 90-m stream segment considered in this study consisted of over 45,000 ground echoes (Figure 1). This gives an average point density of about 2.7 points $/ \mathrm{m}^{2}$ over the 1.67 ha area.
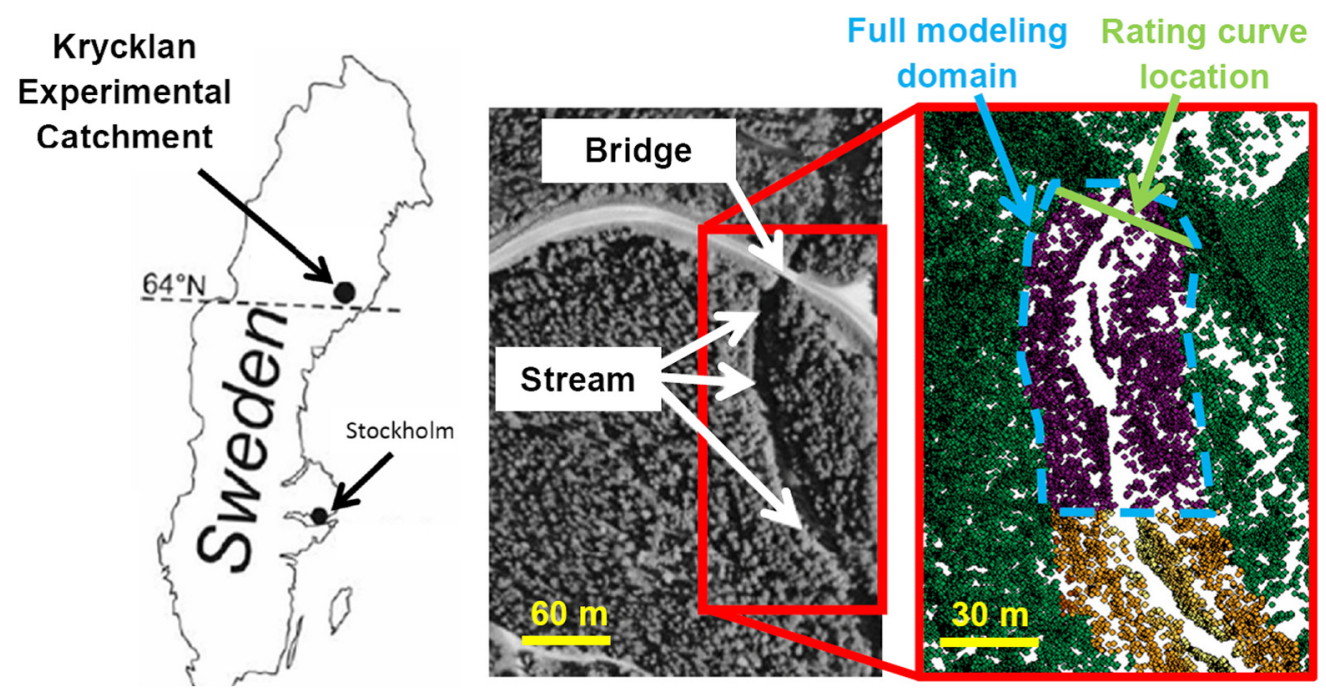

Figure 1. Site map showing the location of the Krycklan experimental catchment in Sweden and the stream section modeled. The green line indicates the location of the cross-section where the rating curve was extracted. There is a non-thinned density of about a 2.7-points $/ \mathrm{m}^{2}$ maximum in the highlighted point cloud that constitutes the main rating curve modeling domain.

\subsection{Methods}

A key issue associated with using ALS data to run a hydraulics-based rating curve model is the resolution of data required to adequately represent the channel geometry. The goal of this study was to investigate the potential of modeling stream flows using a set of synthetically thinned ALS point clouds of the same density as in typical national-scale ALS surveys. This was accomplished in fundamentally two steps. The first consisted of generating realizations of ALS surveys at different resolutions relevant for the study site. The second consisted of using these realizations to model a rating curve. Both steps are described in the following sections.

\subsubsection{Step 1: 3D Point Cloud Thinning of Airborne Laser Scanning Data}

A systematic thinning of information was carried out to synthetically reduce the ALS survey data resolution to a level comparable with the resolution that will be available through the ongoing national 
ALS acquisition of Sweden [6] (www.lantmateriet.se). In this study, we considered two distinct high-resolution ALS survey datasets as the starting point for the systematic thinning. To allow for the consideration of the systematic thinning alone, the first high-resolution starting point consisted of the ALS topography data augmented within the stream channel to account for the inability of the ALS to sense through the stream water. As such, the stream bottom topography was estimated using a detailed topographic survey in the field and merged into the high resolution ALS data before thinning. This surveyed data consisted of 29 cross-sections along the $90-\mathrm{m}$ stream reach utilized in this modeling study. Of course, such a bathymetric profile density would be feasible only for small scales or site-specific investigations. Observations were made using a Trimble S6 DR robotic total station (Trimble Navigation, Limited, 2013), and the linear density of the observations along each of these transects was 3.2 points $/ \mathrm{m}$. These data, where there was a slightly lower average areal point density of $1.0 \mathrm{pt} / \mathrm{m}^{2}$, were merged into the ALS LiDAR point cloud to provide consistent coverage of the stream channel geometry along the entire $90-\mathrm{m}$ stream reach considered.

Clearly, including some detailed bathymetric survey transects may not be representative of the data actually captured during a low-resolution ALS scan. As such, to provide a potentially more representative case, we also considered a second high-resolution starting point consisting of the unaltered ALS topography data. For this second case, it should be noted that a horizontal line was assumed to extend from the lowest available ALS topography point, thereby defining an apparently flat stream bottom, to facilitate subsequent hydraulic rating curve modeling. Nathanson et al. [38] demonstrated that the impact of such a flat bottom assumption was minimal at this location. This was because most of the information with regard to the stream channel's overall shape (particularly, as it is expressed at higher flows) and geometry is measured with the ALS data. It should also be noted that such a flat bottom assumption would likely be too simple for certain river types. Riffle pool-type rivers, for example, show typical patterns of shallow and deep areas that might not be approximated as simple flat bottoms or trapezoidal cross-sections when modeling a rating curve.

The resultant point clouds (what can be considered high-resolution data) were thinned by applying a circular selection with a 3D search radius at each point. The procedure was to identify all points lying within a given radius of randomly selected initial base points and subsequently removing these points. The impact of the initial base points considered as the basis for the thinning was tested through several random realizations of initial base point distributions. There was minimal impact on the initial base point distribution on the resultant thinned point cloud. Thinning was tested for radii ranging from $0.25 \mathrm{~m}$ to $2.00 \mathrm{~m}$, resulting in average point densities ranging from 2.2 points $/ \mathrm{m}^{2}$ to 0.2 points $/ \mathrm{m}^{2}$ (Figure 2a). This allowed for various realizations of ALS data resolution. While all resultant thinned ALS scans were implemented in the hydraulic rating curve modeling (see the following section), only the results for the "most thinned" data, e.g., 0.2 points $/ \mathrm{m}^{2}$ resolution, were retained and are tested in this study. We therefore are considering a worst case scenario relative to the specification of the Swedish ALS mapping project in this pilot study. 
(a)

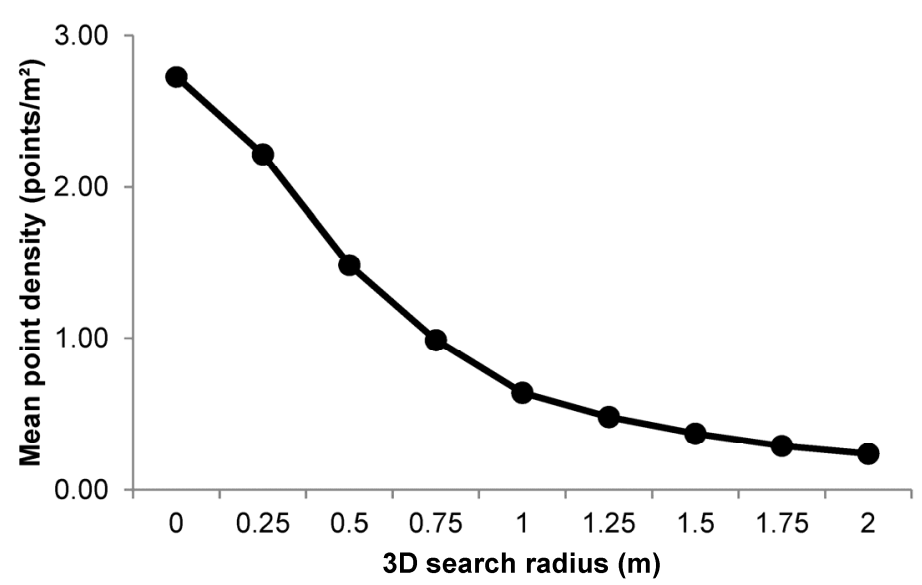

(b)

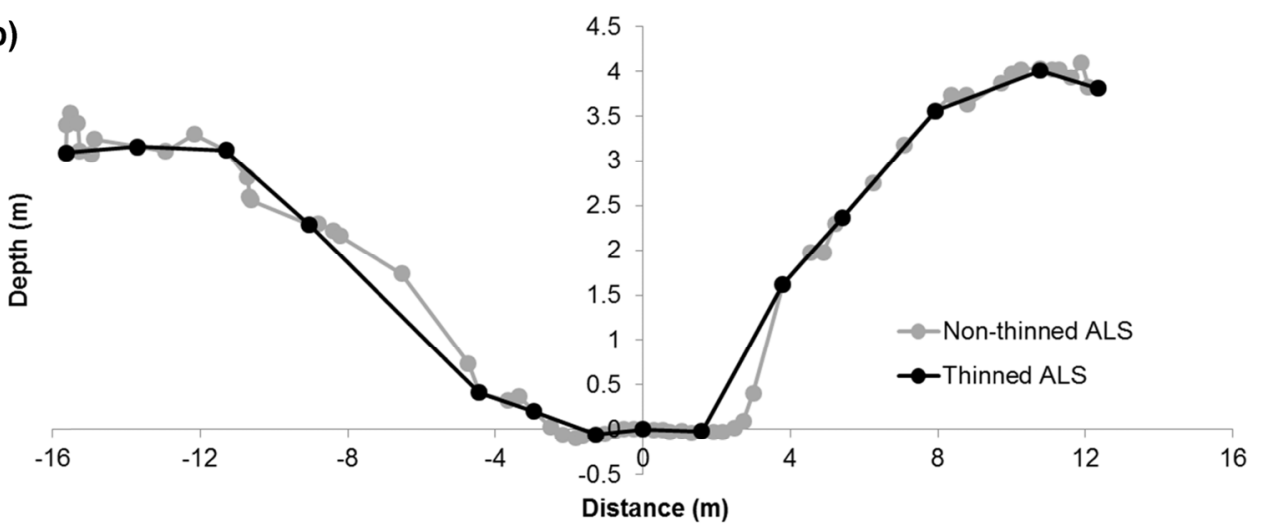

Figure 2. The relation between (a) the 3D search radius and mean point density seen for the thinning of the airborne laser scanning (ALS) data and (b) an example cross-section of the stream from the thinned (black) and non-thinned (grey) survey-augmented ALS data at the location where the rating curves are extracted from the model.

\subsubsection{Step 2: Hydraulic Modeling of Rating Curves}

The thinned ALS and non-thinned ALS data (e.g., the low-resolution and high-resolution elevation data, respectively) were used to implement the hydraulic model of Kean and Smith [44] as outlined in Nathanson et al. [38]. Note that for the high-resolution, non-thinned case, we use the ALS survey augmented by the bathymetric profile survey data, since this provides an absolute best case scenario for the rating curve modeling. Our goal was to determine the influence of data resolution on the modeling of rating curves. The hydraulic model [44] has been developed for calculating rating curves for streams: (1) with bed roughness elements that are small compared to the depth of flow; (2) that may contain rigid bank or floodplain vegetation; and (3) that have width-to-depth ratios of 10 or greater (see [45] for an approach for modeling narrow channels). The estimated rating curve is thus generated using the one-dimensional hydraulic model by computing discharge over the full range of stages across the modeling domain in a two-step procedure. In the first step, contributing factors are quantified, such as: (1) the shape of the channel; (2) the physical roughness of the streambed, banks and floodplain; and (3) the vegetation density on the banks and floodplain. Secondly, the quantified roughness is embedded into a flow model for calculation of the stage-discharge relation. 
As the modeling was implemented in this current study, the shape of the channel and topographic structure are taken from the ALS elevation data. Processing work to interpolate between topographic points in the point cloud data was done using software for the Multi-Dimensional Surface-Water Modeling System (MD_SWMS) available from the U.S. Geological Survey (USGS). As such, this gives three possible channel geometries (two from low-resolution thinned ALS data and one from high-resolution non-thinned ALS data) per the design of our experiment for mapping of the shape of the channel and the bulk roughness elements associated with the spacing of small-scale topographic features on the banks and floodplains. Figure $2 b$ shows an example cross-section of the stream at the position where the representative rating curves were extracted for the non-thinned and thinned survey-augmented data. Boundary (bed) roughness, specified in terms of a roughness height $z_{o}$ for every point on a two-dimensional curvilinear grid of the stream channel within the modeling domain, was back calculated by using a single measurement of low flow discharge and the corresponding water surface slope $[38,45]$. Vegetation densities on the banks and floodplain, which supply a drag force on flows, were measured in the field. Within three randomly selected plots of $10 \mathrm{~m}^{2}$, vegetation density was determined by measuring stem and trunk cross-sectional areas perpendicular to flow (i.e., frontal areas) for vegetation larger than $0.5 \mathrm{~cm}$ in diameter. The average bank and floodplain vegetation density was $0.052 \mathrm{~m}^{-1}$ with an observed range of $0.035 \mathrm{~m}^{-1}$ to $0.069 \mathrm{~m}^{-1}$. The average vegetation density was considered as representative of the entire reach in our modeling, but the impact of the range of densities was considered. The vegetation densities in combination with channel shape information define the physical roughness associated with stream banks and the floodplain implemented in the hydraulic model.

The hydraulic model of Kean and Smith [44] calculates velocity profiles for every submerged grid point on a two-dimensional curvilinear grid that follows the centerline of the channel. This is done at any given cross-section along the stream $(x)$ by solving a version of the St. Venant equations for steady, non-uniform flow $(Q)$ in one dimension for shallow water. The model calculates the water surface profile that simultaneously satisfies both the continuity and momentum equations:

$$
\frac{\partial Q}{\partial x}=0
$$

and

$$
\frac{1}{2} \frac{\partial\left(u^{2}\right)_{a v}}{\partial x}+g \frac{\partial E}{\partial x}+\frac{1}{2} \frac{\left(\tau_{b}\right)_{a v}}{R}=0
$$

where $\left(u^{2}\right)_{a v}$ is the square of the downstream velocity component averaged over the cross-section; $g$ is the acceleration of gravity; $E$ is the surface water elevation; $\left(\tau_{b}\right)_{a v}$ is the perimeter-averaged shear stress and $R$ is the hydraulic radius given by the ratio of the cross-sectional area of the flow to its wetted perimeter [45]. While the first term of Equation (2) describes the streamwise change of velocity, the second term expresses how the pressure gradient changes due to streamwise changes of elevation. The final term accounts for the resistance factors.

As a starting point to simultaneously satisfying Equations (1) and (2), the vertical velocity $(u)$ at any point in the stream reach is calculated as:

$$
u=\left(\frac{\tau_{b}}{\rho}\right)^{1 / 2} \times \beta_{r}=u_{*} \times \beta_{r}
$$


where $\rho$ is water density; $\beta_{r}$ is a non-dimensional roughness coefficient and $\boldsymbol{u}_{*}$ is the shear velocity, which is directly related to the shear stress $(\tau b)$. In streams with steady flow conditions, the shear stress is given by:

$$
\tau_{b}=\rho g h S_{f}
$$

where $h$ is the local flow depth and $S_{f}$ is the friction slope. Under such conditions [45], $\beta_{r}$ will have the form:

$$
\beta_{r}=\frac{\ln \left(\frac{h}{z_{0}}\right)-0.74}{\kappa}
$$

where $\kappa$ is the von Karman constant equal to 0.408 [46]. By combining Equations (3), (4) and (5), the vertical velocity at any point can be calculated as:

$$
u=\sqrt{g h S_{f}} \times \frac{\ln \left(\frac{h}{z_{0}}\right)-0.74}{\kappa}
$$

Equation (6) is thus used to solve the flow field for the entire reach in an iterative manner. This solution can be related to the stage at any cross-section within the modeled stream reach, and repeating the procedure for several stages or flows, a rating curve can be modeled for any position along the stream. This was done for the stream geometries resulting from both thinned and non-thinned ALS data.

\section{Results}

\subsection{Estimation of Rating Curves and Channel Geometry}

The empirical rating curve for the study site has been defined as $Q=3.6 h^{2.5}\left(r^{2}=0.91\right)$ based on about four years of direct observation between 2009 and 2012 [38]. We used these observations and the resulting empirical rating curve as a basis for comparison of the modeled rating curves generated at the stream gage location (Figure 3). There were similarities in the overall shape of the modeled curves and the empirical curve for the range of stages presented. While the root mean squared error between the observed flows and the empirical rating curve was $0.56 \mathrm{~m}^{3} / \mathrm{s}$, it was $0.72 \mathrm{~m}^{3} / \mathrm{s}$ between the observed flows and the rating curve modeled using the non-thinned ALS data augmented with the bathymetry profile surveys. The root mean squared errors were $0.56 \mathrm{~m}^{3} / \mathrm{s}$ between the observed flows and the rating curve modeled using the thinned survey-augmented ALS data and $0.39 \mathrm{~m}^{3} / \mathrm{s}$ between the observed flows and the rating curve modeled using the thinned unaltered ALS data under a flat stream bottom assumption. Although we had anticipated increased error with the thinned ALS data, this was not the case and could indicate the potential for slight bias in the modeling. For both the empirical rating curve and the model rating curves, the average absolute error compared to observed flows tended to increase with increasing stage (Figure 4). 


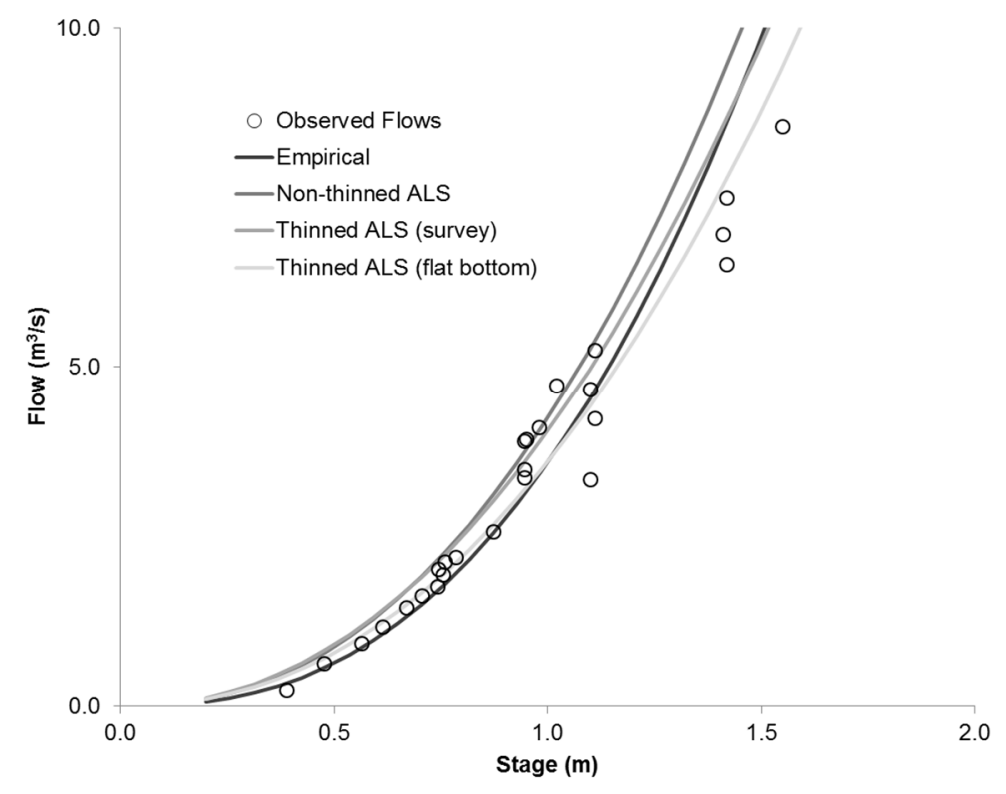

Figure 3. Comparison of the empirical rating curve (black) defined using observed flows (circles) with the rating curves modeled using non-thinned ALS data (dark grey), the thinned survey-augmented ALS data (grey) and the thinned unaltered ALS data assuming a flat stream bottom (light grey).

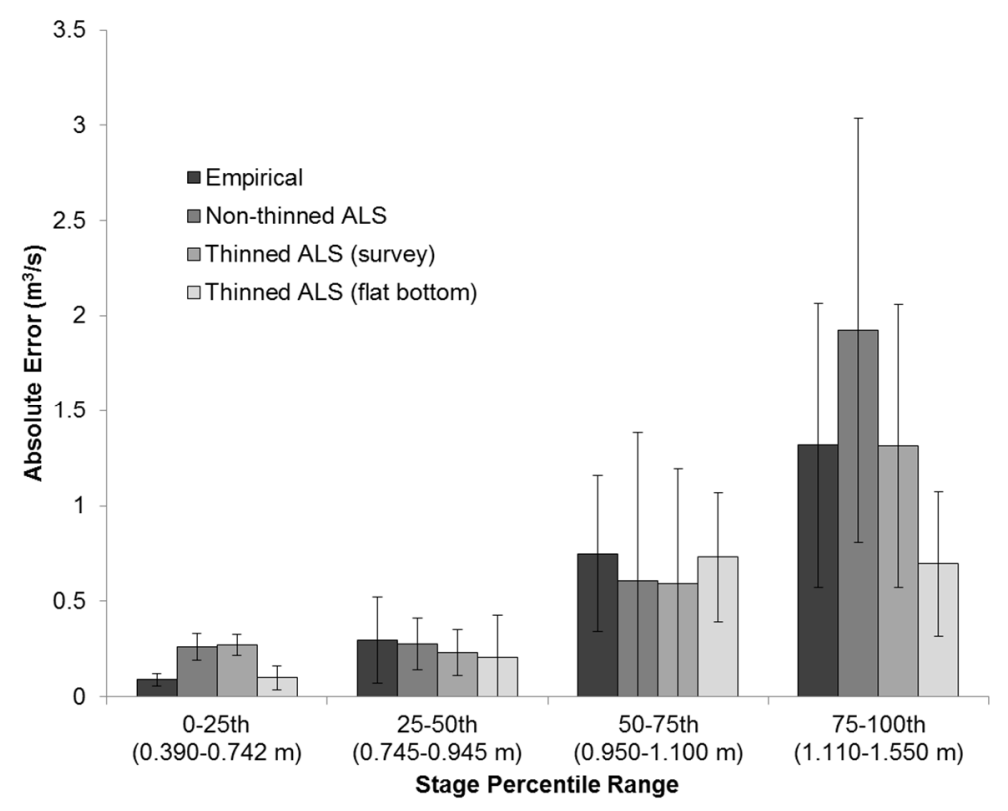

Figure 4. Average absolute error between flow observations and rating curves grouped by quartile of stage. Error bars indicate the standard deviations of the errors within the quartile.

Looking at the channel geometry along the reach, there was some difference between both the thinned and the non-thinned ALS data (Table 1). We can compare at two representative stages. The first corresponds to roughly the average annual flow at the Krycklan catchment outlet of about $1 \mathrm{~m}^{3} / \mathrm{s}$ and a stage of $0.6 \mathrm{~m}$. This flow rate is equivalent to a specific discharge (i.e., flow rate per unit catchment area) of about $1.3 \mathrm{~mm} / \mathrm{d}$, which is similar to observed values reported in Lyon et al. [47]. Furthermore, this flow rate corresponds to an annual runoff of around $475 \mathrm{~mm} / \mathrm{y}$, which is similar to that 
reported in Tetlzaff et al. [48] for the Krycklan catchment. The second stage for comparison was $1.4 \mathrm{~m}$, which corresponds to the most consistently observed maximum flow rate of around $8 \mathrm{~m}^{3} / \mathrm{s}$ during the spring flood. There was variability in geometries and cross-sectional areas along the channel. Still, these differences were small relative to the width and depth of the stream at the same stages.

Table 1. Stream channel properties estimated using non-thinned and thinned ALS data. The reference stage is estimated from the rating curve over the entire section of the stream, and distance is measured downstream from the rating curve cross-section.

\begin{tabular}{|c|c|c|c|c|c|c|c|}
\hline Property & $\begin{array}{c}\text { Distance } \\
(\mathrm{m})\end{array}$ & Non-Thinned & $\begin{array}{l}\text { Thinned } \\
\text { (Survey) }\end{array}$ & $\begin{array}{c}\text { Thinned } \\
\text { (Flat Bottom) }\end{array}$ & Non-Thinned & $\begin{array}{l}\text { Thinned } \\
\text { (Survey) }\end{array}$ & $\begin{array}{c}\text { Thinned } \\
\text { (Flat Bottom) }\end{array}$ \\
\hline Streamflow $\left(\mathrm{m}^{3} / \mathrm{s}\right)$ & & 1.0 & 1.0 & 1.0 & 8.0 & 8.0 & 8.0 \\
\hline Reference Stage (m) & & 0.6 & 0.6 & 0.6 & 1.4 & 1.4 & 1.4 \\
\hline Area $\left(\mathrm{m}^{2}\right)$ & 0 & 3.7 & 4.0 & 2.8 & 11.7 & 12.3 & 8.8 \\
\hline Wetted Perimeter (m) & 0 & 7.9 & 7.8 & 5.8 & 12.2 & 13.2 & 10.4 \\
\hline Hydraulic Radius (m) & 0 & 0.5 & 0.5 & 0.5 & 1.0 & 0.9 & 0.8 \\
\hline Top width (m) & 0 & 7.6 & 7.5 & 7.5 & 11.0 & 12.1 & 10.2 \\
\hline Area $\left(\mathrm{m}^{2}\right)$ & 45 & 2.9 & 3.5 & 3.8 & 10.3 & 11.3 & 10.9 \\
\hline Wetted Perimeter (m) & 45 & 8.4 & 9.1 & 8.5 & 11.1 & 11.6 & 11.1 \\
\hline Hydraulic Radius (m) & 45 & 0.3 & 0.4 & 0.4 & 0.9 & 1.0 & 1.0 \\
\hline Top width (m) & 45 & 8.2 & 8.8 & 8.2 & 10.2 & 10.5 & 9.9 \\
\hline Area $\left(\mathrm{m}^{2}\right)$ & 90 & 1.8 & 2.2 & 4.3 & 9.5 & 10.9 & 11.6 \\
\hline Wetted Perimeter $(\mathrm{m})$ & 90 & 7.8 & 7.9 & 9.2 & 12.0 & 14.1 & 10.9 \\
\hline Hydraulic Radius (m) & 90 & 0.2 & 0.3 & 0.5 & 0.8 & 0.8 & 1.1 \\
\hline Top width (m) & 90 & 7.5 & 7.6 & 8.8 & 11.2 & 12.8 & 9.3 \\
\hline
\end{tabular}

\subsection{Potential Errors Introduced through Using Low-Resolution LiDAR}

We can consider the impact of data resolution as a type of error in the flow estimates. This was done by determining the difference in thinned and non-thinned rating curves as a function of stage. In addition, we considered the impacts of uncertainty in vegetation densities by implementing both the maximum and minimum measured densities in the hydraulic modeling. There was an increase in the impact of using low-resolution LiDAR data with increasing stage for both cases (Figure 5). This is expected due to the non-linear nature of stage-discharge relationships for natural cross-sections. What is important is how this error, and its increase with stage, compares to the estimate of error (or uncertainty) associated with actual streamflow measurements used to define empirical rating curves. Comparing error due to data resolution with the difference between flow observations and the empirical rating curve, we can see that the impact of using low-resolution ALS data is of a similar magnitude. This is particularly true for the lower flows and stages less than $1 \mathrm{~m}$. At higher flows, the error between observed flows and the empirical rating curve is much larger and exhibits a much higher range (due to variability in observations) compared to the error introduced through using low-resolution ALS data.

These potential errors can be translated back into impacts on the hydrograph (Table 2). The empirical rating curve and the modeled rating curves were used to translate daily recorded stage values from 1 May 2008 through 31 October 2013 into flow values. The impact of thinning the ALS data can 
be seen in the maximum flow estimated over this period. Further, the variability (expressed as the ratio of interquartile range to median flow) is larger when using the empirical rating curve than either of the two thinned modeled rating curves over the stages of record. This could be anticipated to some extent given the general shape of the rating curves (Figure 3).

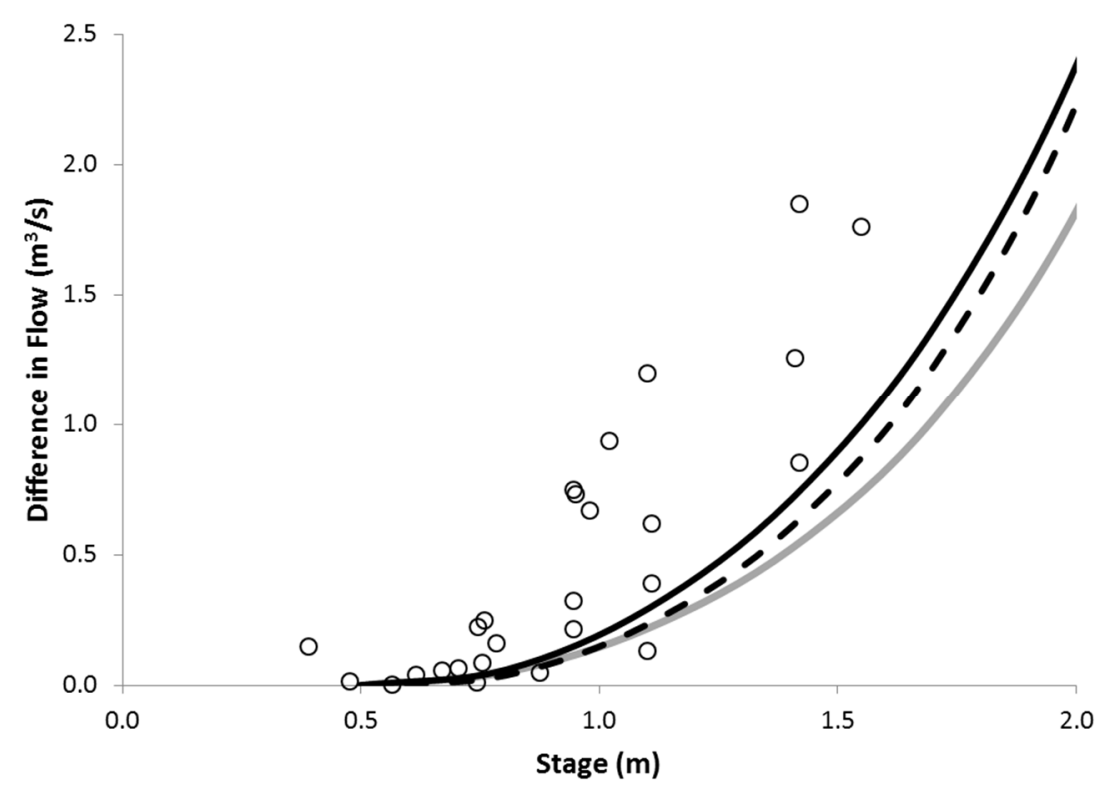

Figure 5. Difference between rating curves modeled using thinned survey-augmented ALS data and non-thinned ALS data as a function of water stage when considering the maximum (black solid) and minimum (black dashed) measured vegetation densities. Difference between rating curves modeled using thinned unaltered ALS data (grey solid) and non-thinned ALS data are shown only for the average vegetation density. These are compared to the difference between observed flows and the empirical rating curve (circles).

Table 2. Summary of hydrograph statistics estimated using the empirical rating curve and the modeled rating curves based on thinned and non-thinned ALS data.

\begin{tabular}{ccccc}
\hline & Empirical & Non-Thinned & Thinned (Survey) & Thinned (Flat Bottom) \\
\hline Maximum $\left(\mathrm{m}^{3} / \mathrm{s}\right)$ & 9.12 & 9.96 & 9.11 & 8.18 \\
Minimum $\left(\mathrm{m}^{3} / \mathrm{s}\right)$ & 0.19 & 0.30 & 0.32 & 0.28 \\
Median $\left(\mathrm{m}^{3} / \mathrm{s}\right)$ & 0.55 & 0.77 & 0.80 & 0.69 \\
Interquartile Range $(\mathrm{IQR})\left(\mathrm{m}^{3} / \mathrm{s}\right)$ & 0.50 & 0.63 & 0.62 & 0.54 \\
IQR/Median $(-)$ & 0.90 & 0.82 & 0.77 & 0.78 \\
\hline
\end{tabular}

\section{Discussion and Concluding Remarks}

For the pilot study considered here, we can theoretically produce model rating curves from low-resolution, national-scale ALS data. The potential error inflicted due to changing the resolution from high to low is on the order of (or less than) that typically associated with establishing and maintaining rating curves for natural cross-sections (Figure 5). In addition, a lack of directly-defined bathymetry (i.e., a flat bottom assumption) does not have significant impact on the ability to model rating curves. Clearly, more work is needed to determine if these findings hold over a range of stream sizes, types 
and landscape settings. Still, the results of this pilot study are encouraging, as they imply that national-scale ALS data could potentially be used to establish rating curves or at least be used to augment ongoing discharge monitoring efforts.

Of course, there are several caveats that must be considered when interpreting or generalizing these results. The conditions under which the ALS data are collected (e.g., flow conditions, snow coverage, weather) will have an impact on not only the quality of the data, but also the ability to define channel geometry. As such, while the loss of geometric channel information considering low-resolution ALS data (Table 1) and the subsequent impact on modeling rating curves (Figure 3 ) were minimal at the current scale and site considered, this may not necessarily hold everywhere and across all scales. When considering scale, the hydraulic modeling employed holds when the hydraulic radius is approximately equal to the average depth (i.e., large width-to-depth ratios). As such, the current application likely pushes the lower bound of spatial scales where such an approach is viable (Table 2) without violation of the hydraulics. Further, the channel geometry simplicity helps make it possible to capture the main channel cross-section elements with low-resolution ALS data (i.e., we can invoke a flat bottom assumption when modeling at this site). This can also be seen as the limitations of data resolution to resolve stream channel geometries at small scales. As a simple thought experiment, we can consider a data resolution of 0.5 points $/ \mathrm{m}^{2}$ and assume a minimum of six aligned points to define a simple trapezoidal stream cross-section. From those assumptions, the theoretically lower limit imposed by data resolution (in the coarsest sense) for modeling a rating curve given the approach considered would be a stream width of $3 \mathrm{~m}$ (about 1/3 the width of the stream considered in this current study). In practice, however, it is not likely that information would be retained regarding in-stream roughness features (micro-topography or large boulders) at such small scales. Furthermore, since these small streams would likely be headwaters with dense vegetation [49], there is increased likelihood that the resolution of the ALS data would be worse than 0.5 points $/ \mathrm{m}^{2}$ (although this might not be an issue in regions above the tree line).

Looking further at vegetation density, the results of this pilot investigation indicate a minimal impact due to vegetation density variability under the flow regimes considered (Figure 5). However, there is still an inherent need to estimate vegetation density for model implementation, which represents a limitation in a truly autonomous sense to wider application of the approach outlined. Further, as vegetation density can change seasonally and inter-annually, there may be need for multiple site visits. These limitations may be overcome in part through remote sensing techniques to estimate vegetation densities, for example those based on ALS scanning (e.g., [50,51]). Finally, it should be noted that the success of this pilot study lies in part with the flow conditions during which the ALS scanning was conducted. The low-flow conditions (less than $0.6 \mathrm{~m}^{3} / \mathrm{s}$ for this stream) during the scanning campaign gave good access to the stream channel allowing for modeling of rating curves across flow regimes (low to high). There, of course, may be a loss in the fidelity of ALS scanning data as water levels change, leading to uncertainty in the resultant modeled rating curves. How this uncertainty propagates across flow regimes and from stage observations through to hydrographs and subsequent identification of, for example, hydrological signatures [52] warrants further consideration.

Regardless of potential difficulties, there appears good potential to utilize low-resolution ALS scanning to model streamflows in larger streams (channel width $>>$ data resolution). The results of this pilot study indicate that using low-resolution ALS data to define the overall floodplain shapes and 
channel dimension would be possible. This information would be very relevant at higher flows when floodplains dominate river responses [53] by providing a physically-based method for constraining rating curve uncertainties. High flows are often the domain of highest uncertainty in discharge time series where clear and significant reductions in uncertainty can be realized via a physical modeling approach (e.g., [54]). The results of this pilot investigation offer a potential way forward leveraging the combination of large-scale ALS data with hydraulic modeling to allow for refinement of rating curve accuracy and streamflow monitoring. Streamflow is one of the most important hydrological variables, but making continuous flow measurements remains challenging. Establishing and maintaining the high-quality rating curves needed for continuously monitoring streamflow and accurately estimating flooding is time consuming and expensive, because flow has to be measured over a range of stages. During flooding and periods of high flow, in particular, measuring flow is nearly impossible (and can often be hazardous), making our ability to accurately estimate flooding extent and impact quite uncertain. There is a worldwide trend towards reducing the number of locations where streamflow is actively monitored [55]. This tendency for reducing monitoring locations comes at the same time as an increase in the interest in terrestrial hydrology and streamflow due to their roles in biogeochemical (carbon) cycling and changes in flood frequency associated with climatic changes. There is clearly a need to develop methods to facilitate the monitoring of streamflow that require little time "in the field" and are both cost effective and safe. Our results demonstrate that it may be possible to employ low-resolution ALS data (similar to that collected within national scanning campaigns) to model stream rating curves using physics-based modeling approaches (e.g., [44]).

\section{Acknowledgments}

This work was supported in the form of funding from the Swedish Research Council (Vetenskapsrådet (VR) Grant No. 2011-4390) and from the Swedish Foundation for International Cooperation in Research and Higher Education (Stiftelsen för internationalisering av högre utbildning och forskning (STINT) Grant No. 2013-5261). In addition, Marcus Nathanson was funded by the Ministry of Education and Research at the Swedish Government and by the Education Administration at the City of Stockholm. The Krycklan Catchment Study is funded by Swedish Science Foundation (SITES), ForWater (Formas), Future Forest, Kempe Foundation, Fortlöpande miljöanalys (FOMA) and Svensk Kärnbränslehantering (SKB). Any use of trade, firm or product names is for descriptive purposes only and does not imply endorsement by the U.S. Government.

\section{Conflicts of Interest}

The authors declare no conflict of interest.

\section{References}

1. Ackermann, F. Airborne Laser Scanning-Present status and future expectations. ISPRS J. Photogramm. Remote Sens. 1999, 54, 64-67.

2. Vosselman, G.; Maas, H.-G. Airborne and Terrestrial Laser Scanning; CRC Press: Boca Raton, FL, USA, 2010. 
3. Kraus, K.; Pfeifer, N. Determination of terrain models in wooded areas with airborne laser scanner data. ISPRS J. Photogramm. Remote Sens. 1998, 53, 193-203.

4. Höfle, B.; Vetter, M.; Pfeifer, N.; Mandlburger, G.; Stötter, J. Water surface mapping from airborne laser scanning using signal intensity and elevation data. Earth Surf. Process. Landf. 2009, 34, 1635-1649.

5. Krishnan, S.; Crosby, C.; Nandigam, V.; Phan, M.; Cowart, C.; Baru, C.; Arrowsmith, R. OpenTopography: A service oriented architecture for community access to LIDAR topography. In Proceedings of the 2nd International Conference on Computing for Geospatial Research and Applications, Washington, DC, USA, 23-25 May 2011.

6. Heerd, R.M.; Kuijlaars, E.A.C.; Zeeuw, M.P.; van't Zand, R.J. Productspecificatie AHN 2000; Rijkswaterstaat AGI: Delft, The Netherlands, 2000.

7. Artuso, R.; Bovet, S.; Streilein, A. Practical methods for the verification of countrywide terrain and surface models. Available online: http://www.isprs.org/proceedings/xxxiv/3-w13/papers/ Artuso_ALSDD2003.pdf (accessed on 18 March 2015).

8. Morville Petersen, Y.; Burman Rost, H. Swedish LiDAR Project. GIM Int. 2011, 2, 21-23.

9. Stoker, J.; Harding, D.; Parrish, J. The need for a national lidar dataset. Photogramm. Eng. Remote Sens. 2008, 74, 1065-1067.

10. Höfle, B.; Rutzinger, M. Topographic airborne LiDAR in geomorphology: A technological perspective. Ann. Geomorphol. 2011, 55, 1-29.

11. Mandlburger, G.; Hauer, C.; Höfle, B.; Habersack, H.; Pfeifer, N. Optimisation of LiDAR derived terrain models for river flow modelling. Hydrol. Earth Syst. Sci. 2009, 13, 1453-1466.

12. Harpold, A.; Lyon, S.W.; Marshall, J. Using LiDAR to Advance Critical Zone Science. Eos Trans. $A G U \mathbf{2 0 1 4}, 95,364$.

13. Marks, K.; Bates, P. Integration of high-resolution topographic data with floodplain flow models. Hydrol. Process. 2000, 14, 2109-2122.

14. Vetter, M. Airborne Laser Scanning Terrain and Land Cover Models as Basis for Hydrological and Hydraulic Studies. PhD Thesis, Vienna Doctoral Programme on Water Resource Systems, Centre for Water Resource Systems, Vienna University of Technology, Vienna University of Technology, Wien, Austria, 15 May 2013.

15. Mackey, B.H.; Roering, J.J.; McKean, J.A. Long-term kinematics and sediment flux of an active earthflow, Eel River, California. Geology 2009, 37, 803-806.

16. Kinzel, P.J.; Wright, C.W.; Nelson, J.M.; Burman, A.R. Evaluation of an experimental LiDAR for surveying a shallow, braided, sand-bedded river. J. Hydraul. Eng. ASCE 2007, 133, 838-842.

17. Snyder, N.P. Studying stream morphology with airborne laser elevation data. Eos 2009, 90, 45-46.

18. French, J.R. Airborne LiDAR in support of geomorphological and hydraulic modelling. Earth Surf. Process. Landf. 2003, 28, 321-335.

19. Brügelmann, R.; Bollweg, A. Laser altimetry for river management. Int. Arch. Photogramm. Remote Sens. Spat. Inf. Sci. 2004, 35, 234-239.

20. Hollaus, M.; Wagner, W.; Kraus, K. Airborne laser scanning and usefulness for hydrological models. Adv. Geosci. 2005, 5, 57-63.

21. Thoma, D.P.; Gupta, S.C.; Bauer, M.E.; Kirchoff, C.E. Airborne laser scanning for riverbank erosion assessment. Remote Sens. Environ. 2005, 95, 493-501. 
22. Jones, A.F.; Brewer, P.A.; Johnstone, E.; Macklin, M.G. High resolution interpretative geomorphological mapping of river valley environments using airborne LiDAR data. Earth Surf. Process. Landf. 2007, 32, 1574-1592.

23. Hyyppä, J.; Holopeinen, M.; Olsson, H. Laser scanning in forests. Remote Sens. 2012, 4, 2919-2922.

24. Maas, H.-G. Forestry Applications. In Airborne and Terrestrial Laser Scanning; Vosselman, G., Maas, H.-G., Eds.; CRC Press: Boca Raton, FL, USA, 2010.

25. Palminteri, S.; Powell, G.V.N.; Asner, G.P.; Peres, C.A. LiDAR measurements of canopy structure predict spatial distribution of a tropical mature forest primate. Remote Sens. Environ. 2012, 127, 98-105.

26. Hunter, N.; Bates, P.; Neelz, S.; Pender, G.; Villanueva, I.; Wright, N.; Liang, D.; Falconer, R.; Lin, B.; Waller, S.; et al. Benchmarking 2D hydraulic models for urban flooding. Water Manag. 2008, $161,13-30$.

27. Turner, A.B.; Colby, J.D.; Csontos, R.M.; Batten, M. Flood Modeling Using a Synthesis of Multi-Platform LiDAR Data. Water 2013, 5, 1533-1560.

28. Asner, G.P.; Mascaro, J.; Muller-Landau, H.C.; Vieilledent, G.; Vaudry, R.; Rasamoelina, M.; van Breugel, M. A universal airborne LiDAR approach for tropical forest carbon mapping. Oecologia 2012, 168, 1147-1160.

29. Bremer, M.; Rutzinger, M.; Wichmann, V. Derivation of tree skeletons and error assessment using LiDAR point cloud data of varying quality. ISPRS J. Photogramm. Remote Sens. 2013, 80, 39-50.

30. Maas, H.-G.; Bienert, A.; Scheller, S.; Keane, E. Automatic forest inventory parameter determination from terrestrial laser scanner data. Int. J. Remote Sens. 2008, 29, 1579-1593.

31. Cobby, D.M.; Mason, D.C.; Horritt, M.S.; Bates, P.D. Two-dimensional hydraulic flood modelling using a finite-element mesh decomposed according to vegetation and topographic features derived from airborne scanning laser altimetry. Hydrol. Process. 2003, 17, 1979-2000.

32. Mason, D.C.; Cobby, D.M.; Horritt, M.S.; Bates, P.D. Floodplain friction parameterization in two-dimensional river flood models using vegetation heights derived from airborne scanning laser altimetry. Hydrol. Process. 2003, 17, 1711-1732.

33. Antonarakis, A.S. The Potential of LiDAR in Recovering Physical Data on Floodplain Vegetation to Parameterise Flow Resistance. Ph.D. Thesis, Cambridge University, UK, 6 May 2008.

34. Kouwen, N. Field estimation of the biomechanical properties of grass. J. Hydraul. Res. 1988, 26, 559-568.

35. Kouwen, N.; Fathi-Moghadam, M. Friction factors for coniferous trees along rivers. J. Hydraul. Eng. ASCE 2000, 126, 732-740.

36. Abu-Aly, T.R.; Pasternack, G.B.; Wyrick, J.R.; Barker, R.; Massa, D.; Johnson, T. Effects of LiDAR-derived, spatially distributed vegetation roughness on two-dimensional hydraulics in a gravel-cobble river at flows of 0.2 to 20 times bankfull. Geomorphology 2014, 206, 468-482.

37. Katul, G.G.; Wiberg, P.; Albertson, J.; Hornberger, G. A mixing layer theory for flow resistance in shallow streams. Water Resour. Res. 2002, 38, doi:10.1029/2001WR000817.

38. Nathanson, M.; Kean, J.W.; Grabs, T.J.; Seibert, J.; Laudon, H.; Lyon, S.W. Modeling rating curves using remotely sensed LiDAR data. Hydrol. Process. 2012, 26, 1427-1434. 
39. Laudon, H.; Taberman, I.; Ågren, A.; Futter, M.; Ottosson-Löfvenius, M.; Bishop, K. The Krycklan Catchment Study-A flagship infrastructure for hydrology, biogeochemistry and climate research in the boreal landscape Water Resour. Res. 2013, 49, 1-5.

40. Bishop, K.H.; Grip, H.; O’Neill, A. The origins of acid runoff in a hillslope during storm events. J. Hydrol. 1990, 116, 35-61.

41. Lyon, S.W.; Laudon, H.; Seibert, J.; Mörth, M.; Tetzlaff, D.; Bishop, K.H. Controls on snowmelt water mean transit times in northern boreal catchments. Hydrol. Process. 2010, 24, 1672-1684.

42. Grabs, T.; Bishop, K.; Laudon, H.; Lyon, S.W.; Seibert J. Riparian zone hydrology and soil water total organic carbon (TOC): Implications for spatial variability and upscaling of lateral riparian TOC exports. Biogeosciences 2012, 9, 3901-3916.

43. Blom, S.A.T.A. Projektrapport 1110 Krycklan; 1110 Krycklan: Gothenburg, Sweden, 2008.

44. Kean, J.W.; Smith, J.D. Calculation of stage-discharge relations for gravel bedded channels. J. Geophys. Res. Earth Surf. 2010, 115, 1-15.

45. Kean, J.W.; Smith, J.D. Generation and verification of theoretical rating curves in the Whitewater River basin, Kansas. J. Geophys. Res. 2005, 110, 1-17.

46. Long, C.E.; Wiberg, P.L.; Nowell, A.R.M. Evaluation of von Karman's constant from integral flow parameters. J. Hydraul. Eng. ASCE 1993, 119, 1182-1190.

47. Lyon, S.W.; Nathanson, M.; Spans, A.; Grabs, T.; Laudon, H.; Temnerud, J.; Bishop, K.; Seiber, J. Specific discharge variability in a boreal landscape. Water Resour. Res. 2012, 48, doi:10.1029/2011WR011073.

48. Tetzlaff, D.; Soulsby, C.; Buttle, J.; Capell, R.; Carey, S.K.; Laudon, H.; McDonnell, J.; McGuire, K.; Seibert, S.; Shanley, J. Catchments on the cusp: Structural and functional change in northern ecohydrology. Hydrol. Process. 2013, 27, 766-774.

49. Bishop, K.; Buffam, I.; Erlandsson, M.; Fölster, J.; Laudon, H.; Seibert, J.; Temnerud, J. Aqua Incognita: The unknown headwaters. Hydrol. Process. 2008, 22, 1239-1242.

50. Edson, C.; Wing, M.G. Airborne Light Detection and Ranging (LiDAR) for Individual Tree Stem Location, Height, and Biomass Measurements. Remote Sens. 2011, 3, 2494-2528.

51. Maltamo, M.; Eerikäinen, K.; Packalén, P.; Hyyppä, J. Estimation of stem volume using laser scanning-based canopy height metrics. Forestry 2006, 79, doi:10.1093/forestry/cp1007.

52. McMillan, H.K.; Westerberg, I.K. Rating curve estimation under epistemic uncertainty. Hydrol. Process. 2015, 29, doi:10.1002/hyp.10419.

53. Graf, W.L. Damage control: Restoring the physical integrity of America's rivers. Ann. Assoc. Am. Geogr. 2001, 91, 1-27.

54. Di Baldassarre, G.; Claps, P. A hydraulic study on the applicability of flood rating curves. Hydrol. Res. 2011, 42, 10-19.

55. Brown, K. Water scarcity: Forecasting the future with spotty data. Science 2002, 297, 926-927.

(C) 2015 by the authors; licensee MDPI, Basel, Switzerland. This article is an open access article distributed under the terms and conditions of the Creative Commons Attribution license (http://creativecommons.org/licenses/by/4.0/). 